\title{
Effect of High Hydrostatic Pressure Processing on the Chemical Characteristics of Different Lamb Cuts
}

\author{
Kevin Kantono ${ }^{1}{ }^{(}$, Nazimah Hamid ${ }^{1}$,*(D) Indrawati Oey ${ }^{2,3}{ }^{\circledR}$, Yan Chao Wu ${ }^{1}$, Qianli Ma ${ }^{1,4}$, \\ Mustafa Farouk ${ }^{5}$ and Diksha Chadha ${ }^{1}$ \\ 1 Department of Food Science and Microbiology, Auckland University of Technology, Auckland 1010, \\ New Zealand; kkantono@aut.ac.nz (K.K.); ycw@aut.ac.nz (Y.C.W.); mq1201228@163.com (Q.M.); \\ diksha.chadha@aut.ac.nz (D.C.) \\ 2 Department of Food Science, University of Otago, Dunedin 9016, New Zealand; indrawati.oey@otago.ac.nz \\ 3 Riddet Institute, Massey University, Palmerston North 4474, New Zealand; mustafa.farouk@agresearch.co.nz \\ 4 Institute of Food Science and Technology, Chinese Academy of Agricultural Sciences, Key Laboratory of \\ Agro-Products Processing, Ministry of Agriculture and Rural Affairs, Beijing 100193, China \\ 5 AgResearch MIRINZ, Ruakura Research Centre, Private Bag 3123, Hamilton 3240, New Zealand; \\ mustafa.farouk@agresearch.co.nz \\ * Correspondence: nazimah.hamid@aut.ac.nz; Tel.: +64-9-9219999 (ext. 6453); Fax: +64-9-9219627
}

Received: 16 August 2020; Accepted: 1 October 2020; Published: 12 October 2020

\begin{abstract}
The non-thermal high-pressure processing (HPP) technique has been used to increase the shelf life of food without compromising their nutritional and sensory qualities. This study aims to explore the potential application of HPP on New Zealand lamb meat. In this study, the effect of HPP, at different pressure treatments (200-600 MPa) on eight different lamb meat cuts in terms of lipid oxidation, fatty acid and free amino acid content were investigated. In general treatments between 400 and 600 MPa resulted in higher oxidation values in eye of loin, flat, heel, and tenderloin cuts. Saturated and monounsaturated fatty acid content were significantly lower with HPP treatment of almost all cuts (except rump and heel cuts) at all pressures. Polyunsaturated fatty acid content was significantly lower in HPP-treated inside, knuckle, and tenderloin cuts at $600 \mathrm{MPa}$ compared to control. Nine essential free amino acids (valine, leucine, isoleucine, methionine, phenylalanine, lysine, histidine, tyrosine and tryptophan), and eight non-essential free amino acids (alanine, glycine, threonine, serine, proline, aspartic acid, glutamic acids and ornithine) were identified in the lamb cuts. HPP increased the total free amino acid composition significantly compared to control at all pressures for almost all cuts except the inside and eye of loin cuts. This study suggests that higher pressure treatments (i.e., 400 and $600 \mathrm{MPa}$ ) resulted in higher TBARS oxidation levels. Additionally, significant decreases in saturated and monounsaturated fatty acids and increase free amino acid content were observed in the majority of HPP-treated samples compared to control.
\end{abstract}

Keywords: high-pressure processing; lamb cuts; fatty acids; amino acids; lipid oxidation

\section{Introduction}

Lipid oxidation can adversely affect the quality of meat and meat products during processing and may confer negative effects on colour [1], flavour [2], and nutrition [3]. Hence, with the use of high pressure to improve the functional properties and quality of lipids and meat products $[4,5]$, monitoring lipid oxidation in high-pressure-treated meat is necessary for successful implementation of HPP technology in the meat industry. Increased oxidation of pressure-treated pork was significant at high pressures that exceeded 300MPa [6]. Angsupanich and Ledward [7] also reported an increase in lipid oxidation at $400 \mathrm{MPa}$ and higher pressures at ambient temperature in cod muscle. It was further found that the pressure required to initiate lipid changes in turkey [8] and beef muscle was lower 
(200 MPa) [9] than that required for pork and chicken. Beltran et al. [8] reported that pressure treatment of minced chicken breast at pressures up to $500 \mathrm{MPa}$ had no significant effect on lipid oxidation. Chicken breast meat was found to have more oxidative stability than turkey muscle. Pressure was also found to induce lipid oxidation during subsequent storage of meat [8]. Wang et al. [10] evaluated the effect of high pressure treatment on lipid oxidation and composition of fatty acids in yak body fat at 4 and $15^{\circ} \mathrm{C}$ for up to 20 days of storage. At the end of storage, 400 and $600 \mathrm{MPa}$ treatments increased the level of thiobarbituric acid reactive substances (TBARS) by $335 \%$ and $400 \%$, respectively, indicating increased lipid oxidation [10]. The mechanism that induces lipid oxidation during HPP treatment is little understood. It has been reported that the release of haem molecules through membrane disruption can trigger lipid oxidation [11].

The fatty acid composition of lipids can influence meat quality [12]. Fatty acid composition contributes to quality traits of meat, such as nutritional value, as well as flavour, and textural properties. It varies widely depending on species, degree of trimming, nature of processing or cooking, and preservation techniques employed [13]. Schmid [3] indicated that most common meats (lamb, beef, pork) have a similar proportion of saturated ( $45 \%$ to $50 \%)$ and monounsaturated fatty acids ( $38 \%$ to $43 \%$ ) and provide a small quantity of polyunsaturated fatty acids (12\% to $20 \%)$. Recent studies have investigated the effects of HPP on fatty acid composition. Most researchers [14-16] found that HPP treatment in meat had no significant effects on the fatty acid composition of the total lipids. However, that does not necessarily mean it did not have any significant effect on the phospholipids, triglycerides and free fatty acids. In most studies, HPP-treated samples generally oxidised more rapidly, with little changes in fatty acid composition. However, the critical pressures that influence oxidation can vary with food type. Yagiz et al. [16] reported no significant differences between control and HPP-treated Atlantic salmon dark muscle in terms of total saturated fatty acids (SFAs), monounsaturated fatty acids (MUFAs), as well as n-3 and n-6 polyunsaturated fatty acids (PUFAs). Kang et al. [17] similarly reported no significant differences in the fatty acid content of control and HPP-treated Korean black goat meat samples. Only Wang et al. [10] reported significantly low PUFAs in pressure-treated yak body fat with $600 \mathrm{MPa}$ treatment. McArdle et al. [18], on the other hand, reported significantly higher PUFA/SFA ratios of pressurised samples compared to control samples, with the exception of milder treatments $\left(20^{\circ} \mathrm{C}\right.$ at 200 and $\left.400 \mathrm{MPa}\right)$. Ono et al. [19] only reported an increase in the PUFA/SFA ratio of cooked beef samples compared to raw meat.

Muscle proteins are susceptible to oxidative reactions that may result in loss of essential amino acids and a decrease in protein digestibility. Although the mechanisms and reaction pathways for lipid and protein oxidation are different, they are both influenced by similar prooxidant and antioxidant factors [20]. High pressures between 100 and $300 \mathrm{MPa}$ for $10 \mathrm{~min}$ at $25^{\circ} \mathrm{C}$ increased the overall autolytic activity of raw beef meat, resulting in a higher concentration of free amino acids [21]. Suzuki et al. [2] reported that serine, glutamic acid, glutamine, glycine and alanine content in lean beef meat gradually increased with increasing pressure, up to $200 \mathrm{MPa}$. However, no significant differences in all 10 amino acids investigated were observed, suggesting that high-pressure treatment did not influence amino acid composition. Campus et al. [22] investigated the effect of $\operatorname{HPP}(300,350$, and 400MPa) on slicedand vacuum-packaged commercial dry-cured pork loin. Only untreated samples showed an increase in free amino acid content during vacuum storage. In fact, application of high pressures (300 to $400 \mathrm{MPa}$ for $10 \mathrm{~min}$ at $20^{\circ} \mathrm{C}$ ) was reported to stabilize free amino acid content during storage due to a reduction in amino peptidase activity.

Although researchers have assessed the impact of HPP on meat quality, limited research has been carried out to investigate the effect of HPP on different lamb meat cuts. The aim of this study is to investigate the effects of high hydrostatic pressure processing (HPP) treatments (200-600 MPa) of eight different lamb cuts on lipid oxidation, fatty acid and free amino acid content. This would help provide an understanding of the chemical changes that may influence the quality of different lamb cuts with HPP treatments. 


\section{Materials and Methods}

\subsection{Preparation of Lamb Samples}

Eight meat cuts, inside (M. semimembranosus), heel (M. gastrocnemius), knuckle (M. quadriceps femoris), rump (M. gluteus medius), tenderloin (M. psaos major), eye of loin (M. longissimus), bolar (M. infraspinatus) and flat (M. bicep femoris) were obtained from six lambs (cold carcasses with a weight of 140.5 to $150.5 \mathrm{~kg}$ ) at $48 \mathrm{~h}$ postmortem. The animals were obtained from AgResearch (Hamilton), and carcass cutting, packaging as well as freezing were carried out there. Each muscle was divided into five blocks and vacuum-packed in polyethylene plastic bags labelled: Control, HPP-200, HPP-300, HPP-400 and HPP-600, and immediately frozen at $-18^{\circ} \mathrm{C}$ in a digitally temperature-controlled thermostat freezer with a static flow cold air temperature of $-20{ }^{\circ} \mathrm{C}$ for HPP processing. Samples were thawed overnight at $4{ }^{\circ} \mathrm{C}$ prior to HPP treatment. In summary, eight different muscles $\left(n_{\text {muscle }}=8\right)$ were divided into five separate parts $\left(\mathrm{n}_{\text {parts }}=5\right)$ from a sample population of six lambs $\left(\mathrm{n}_{\text {lambs }}=6\right)$; therefore, a total of 240 samples were retrieved, and their physicochemical properties were then analysed in triplicate.

The lambs were all rams from a Coopworth base/composite flock; from weaning, they were run in one mob under commercial conditions on pasture. Lambs were approximately 32 weeks of age at slaughter. The lambs were slaughtered under commercial conditions at a New Zealand meat processing plant (average live weight of $44 \mathrm{~kg}$ ). Pilot testing was also carried out to investigate the variance between samples. Our pilot results suggest that the variances between animals were small and did not reach statistical significance. HPP processing parameters were selected based on the ranges that had been used in previously published studies.

\subsection{HPP Processing}

Each of the eight different frozen lamb cuts that were vacuum-packed were thawed overnight prior to HPP treatment. Pressurization of lamb was conducted using an industrial scale HPP equipment (HPP 055, Multivac, Multivac Sepp Haggenmüller GmbH \& Co., Wolferschwenden, Germany). Water was used as the pressure-transmitting medium, with the initial temperature around $7-8{ }^{\circ} \mathrm{C}$. The temperature reached after pressure build-up was less than $25^{\circ} \mathrm{C}$. The rate of pressure build-up was conducted at $125 \mathrm{MPa} / \mathrm{min}$. Packaged lamb samples were loaded in a cylindrical loading container and HPP-treated at 200, 300, 400, 500 and $600 \mathrm{MPa}$. Pressure was held for one minute once the targeted pressure was achieved. After depressurisation, all samples were transported and stored at $-20^{\circ} \mathrm{C}$ for further analysis.

\subsection{Lipid Oxidation}

The 2-thiobarbituric acid reactive substances (TBARS) method to assess lipid oxidation was carried out according to Nam and Ahn [23]. The method was modified by measuring the amount of malondialdehyde (MDA) present in the sample and carried out as described by Faridnia et al. [24]. Minced meat samples (3.0 g) were homogenised using a homogenizer mixer (Janke Kunkel IKA Labortechnik Ultra Turrax T25) in $9.0 \mathrm{~mL}$ deionised distilled water at 14,000 rpm for $30 \mathrm{~s}$. Lamb homogenate $(1 \mathrm{~mL})$ was obtained and transferred to a disposable test tube. This was followed by addition of $50 \mu \mathrm{L}$ of butylated hydroxytoluene (BHT; 7.2\% $w / v$ in ethanol) and $2 \mathrm{~mL}$ thiobarbituric acid (TBA)/trichloroacetic acid (TCA) solution (20 mM TBA and 15\% (w/v) TCA). The mixture was vortexed and then incubated in a $90^{\circ} \mathrm{C}$ water bath for $30 \mathrm{~min}$ until a pink colour was observed. Samples were then cooled down in a water and ice bath for $10 \mathrm{~min}$ and centrifuged at $3500 \mathrm{rpm}$ for $15 \mathrm{~min}$ at $5{ }^{\circ} \mathrm{C}$. The absorbance of the resulting upper layer was measured at $531 \mathrm{~nm}$ using a spectrophotometer (Ultraspec 7000 Pro spectrophotometer, Biochrom Ltd., Cambridge, England, UK) against a blank prepared with $1 \mathrm{~mL}$ deionised water and $2 \mathrm{~mL}$ TBA/TCA solution. The results obtained was expressed as 2-thiobarbituric acid reactive substances (TBARS) in mg malondialdehyde (MDA) per $\mathrm{kg}$ of meat using a tetraethoxypropane (TEP) standard calibration curve. 


\subsection{Fatty Acid Methyl Ester (FAME) Analysis}

Quantification of total fatty acids was carried out according to Juárez et al. [25] by acid hydrolysis of lipids in lyophilized samples to release free fatty acids. This is followed by in situ esterification to fatty acid methyl esters (FAMEs), and their extraction into toluene for analysis by gas chromatography (GC). Samples were lyophilized for $48 \mathrm{~h}$ until completely dried. Then, approximately 20-mg samples were weighed into $10 \mathrm{~mL}$ test tubes, and the weight was recorded. A $10 \mu \mathrm{L}$ aliquot of $2 \mathrm{~g} / \mathrm{L}$ tridecanoic acid in toluene was added as internal standard followed by further addition of $490 \mu \mathrm{L}$ of toluene and $750 \mu \mathrm{L}$ of freshly prepared $5 \%$ methanolic $\mathrm{HCl}$. The mixture was mixed using a vortex, and the headspace of each tube was filled with nitrogen. The tubes were then sealed and incubated in a water bath at $70{ }^{\circ} \mathrm{C}$ for $2 \mathrm{~h}$. After tubes were cooled down to room temperature, $1 \mathrm{~mL}$ of $6 \%$ aqueous $\mathrm{K}_{2} \mathrm{CO}_{3}$ and $500 \mu \mathrm{L}$ toluene were added. The mixture was vortex-mixed and then centrifuged at $1500 \times \mathrm{g}$ rpm for $5 \mathrm{~min}$. The organic phase was then removed using a glass Pasteur pipette for analysis of FAME content.

For fatty acid analysis, a Shimadzu GC-17A gas chromatograph equipped with an FID and a FAMEWAX column $(30 \mathrm{~m} \times 0.32 \mathrm{~mm} \times 0.25 \mu \mathrm{m}$, RESTEK, Inc., Austin, TX, USA) was used. Nitrogen was used as a carrier gas. The pressure was set to $43 \mathrm{~Pa}$, and the flow rate was $7 \mathrm{~mL} / \mathrm{min}$. The oven temperature was held for $5 \mathrm{~min}$ at $140{ }^{\circ} \mathrm{C}$, increased to $245^{\circ} \mathrm{C}$ at $3.5^{\circ} \mathrm{C} / \mathrm{min}$, and held for $3 \mathrm{~min}$ at this temperature.

\subsection{Free Amino Acids}

Methanol (1 mL) was used to extract free amino acids (FAA) from freeze-dried meat samples according to Penet et al. [26], with modifications. Meat samples $(0.1 \mathrm{~g})$ were weighed into a centrifuge tube, and $1 \mathrm{~mL}$ of methanol was added. The mixture was vortexed and then centrifuged at $2000 \times \mathrm{g}$ for 2 min. A commercial free amino acid kit (EZ:faast ${ }^{\mathrm{TM}}$, Phenomenex ${ }^{\circledR}$, Torrance, CA, USA) was used to profile amino acids (user manual shown in the Appendix). All steps, including the solid phase extraction (SPE) sample clean-up, elution from SPE sorbent, derivatisation, and analysis, were performed as described in the manual provided. Additionally, $0.2 \mathrm{mM}$ Norvaline in N-propanol solution was used as an internal standard.

Free amino acid derivatives were analysed using the EZ:faast ${ }^{\mathrm{TM}}$ GC-MS Free Amino Acid kit (Phenomenex, Torrance, CA, USA). A Shimadzu GC2010 GC, equipped with a ZB-AAA GC column $10 \mathrm{~m} \times 0.25 \mathrm{~mm} \times 0.25 \mathrm{um}$ (Phenomenex, Torrance, CA, USA), was used. The instrument settings used are described in the EZ:faast user manual with modifications. Briefly, the derivatised samples $(1 \mu \mathrm{L})$ were injected into the GC column. The GC temperature program was set at an initial oven temperature of $120^{\circ} \mathrm{C}$ (split ratio of $1: 15$ ), raised to $165^{\circ} \mathrm{C}$ at a rate of $5{ }^{\circ} \mathrm{C}$ per minute, and further increased at a rate of $20^{\circ} \mathrm{C}$ per minute to reach $320^{\circ} \mathrm{C}$, where it was held for $1 \mathrm{~min}$. A mixture of 26 amino acids, ranging from 50 to $400 \mathrm{nmol} / \mathrm{mL}$, was used for identification and quantification. The concentration of each amino acid identified in the samples was reported as $\mathrm{mg}$ of amino acid in $1 \mathrm{~g}$ of lamb sample.

\subsection{Statistical Analysis}

The experimental data in this study was collated using Microsoft Office Excel 2011 and subjected to statistical analysis using XLSAT 2020 (Addinsoft, New York, NY, USA). Shapiro-Wilk's normality test was applied to check the normality of the data. The data collected in this study were found to be normal; hence, parametric statistical methods were applied. Analysis of variance (ANOVA) was carried out at the 0.05 level of significance to analyse the effect of HPP processing (control, P200, P300, P400 and P600) on lipid oxidation, fatty acid, and amino acid content in 8 different lamb-cut samples (tenderloin $(\mathrm{T})$, rump $(\mathrm{R})$, knuckle $(\mathrm{K})$, inside $(\mathrm{I})$, heel $(\mathrm{H})$, flat (F), eye of loin (E) and bolar (BL) muscles). A two-way analysis of variance was carried out on the fatty acid profiles for each pressure treatment. When ANOVA was significant ( $p$-values less than 0.05 ), means were separated by pairwise comparison using Fisher's least significant difference test. 
Additionally, multiple factor analysis (MFA) was carried out in order to summarise how the different meat cuts and HPP pressure treatments influenced fatty acid and free amino acid content in this study. MFA is a common statistical tool used to analyse multiple data tables that measure sets of variables collected on the same samples simultaneously, which enables the investigation of relationships between datasets for the variables, namely, amino acids, fatty acids, and TBARS. MFA utilises PCA, which was carried out for each variable of the various data tables [27]. The first eigenvalues of each PCA were then used to weight the various tables. After each PCA was carried out, a weighted PCA on the columns of all tables was carried out.

\section{Results and Discussion}

\subsection{Lipid Oxidation}

\subsubsection{Lipid Oxidation in Different Cuts of Meat}

Lipid oxidation is a very important factor that affects lamb meat quality and acceptance [28]. As lipid content may vary in different animal muscles, the level of lipid oxidation may vary as well. Other factors that can influence the level of lipid oxidation include breed, age, and gender. In this study, the lipid oxidation levels of eight different cuts (flat $(\mathrm{F})$, tenderloin $(\mathrm{T})$, rump $(\mathrm{R})$, knuckle $(\mathrm{K})$, bolar (BL), inside (I), heel (H) and eye of loin (E)) subjected to HHP (0, 200, 300, 400 and $600 \mathrm{MPa})$ were determined.

In this study, there were significant differences in the overall oxidation level with the eight different cuts. According to Park et al. [29], TBARS values varied with pork meat cuts (belly and loin). Oxidation values of belly cuts were significantly higher than loin. In contrast, Kannan et al. [1] reported no significant differences in overall oxidation level in leg shoulder (cut heel), arm (cut flat), and loin/rib (cut eye of loin) cuts of goat meat.

According to Wood et al. [30], TBARS values above $0.5 \mathrm{mg} \mathrm{MDA} / \mathrm{kg}$ will produce a rancid flavour that can be detected by consumers. All the values in control cut samples were below $0.5 \mathrm{mg}$ MDA $/ \mathrm{kg}$ (0.13 to $0.33 \mathrm{mg}$ MDA $/ \mathrm{kg}$ ). Similarly, Rhee et al. [31] reported values between 0.24 to $0.35 \mathrm{mg}$ $\mathrm{MDA} / \mathrm{kg}$ in beef longissimus dorsi (eye of loin), psoas major (tenderloin), semimembranosus (inside), and semitendinosus (heel) muscles. Figure $1 \mathrm{~A}$ shows that flat $(0.33 \mathrm{mg} \mathrm{MDA} / \mathrm{kg})$, tenderloin $(0.30 \mathrm{mg}$ $\mathrm{MDA} / \mathrm{kg})$ and rump cuts $(0.29 \mathrm{mg} \mathrm{MDA} / \mathrm{kg})$ had significantly higher TBARS values than other cuts. Heel and eye of loin cuts, on the other hand, had significantly the lowest TBARS value. These findings are supported by Badiani et al. [32], who reported that flat cut had the highest lipid content compared to eye of loin and heel cuts of raw beef muscles. Rhee et al. [31] further reported that the extent of porcine muscle lipids to undergo lipid oxidation may vary substantially among the same retail cuts and different animals even if the postmortem history of the meat is similar. Results of lipid oxidation from this study on different lamb cuts supports this notion. 

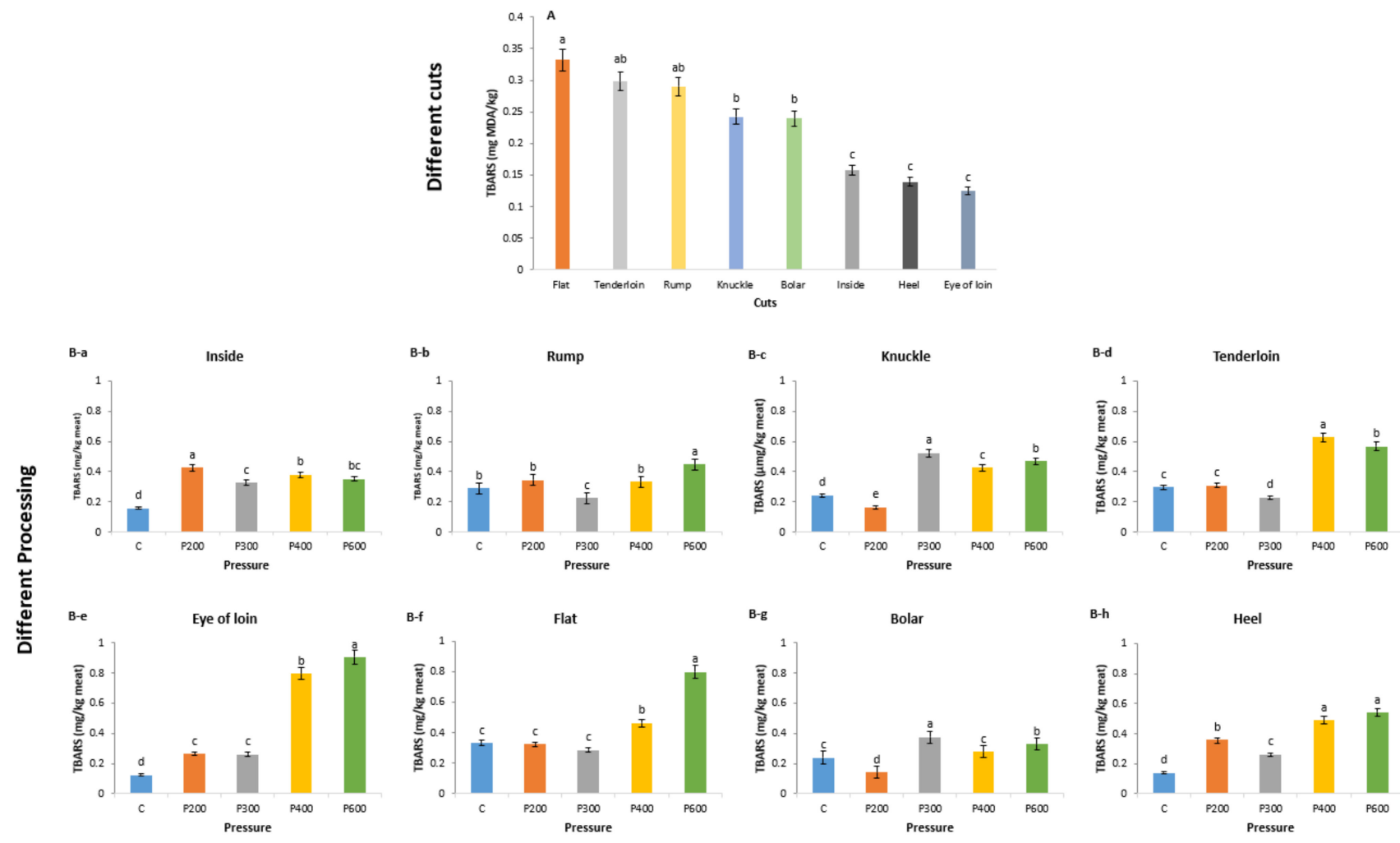

Figure 1. Lipid oxidation marker (thiobarbituric acid reactive substances (TBARS) in different lamb cuts and high-pressure processing samples. (A) different cuts and (B) different processing means of TBARS value with different cut samples (B-a-B-h) differ significantly using Fisher's least significant difference $(p<0.05)$. 


\subsubsection{Effect of Different HPP Treatments on Lipid Oxidation of Different Lamb Cuts}

HPP treatment at higher pressures resulted in some samples having high TBARS values, exceeding $0.5 \mathrm{mg} \mathrm{MDA} / \mathrm{kg}$, that can contribute to rancid flavour [30,33,34]. Specifically, the eye of loin cuts (Figure 1B-e) had significantly the highest MDA values when treated at $400 \mathrm{MPa}$ $(0.80 \mathrm{mg} \mathrm{MDA} / \mathrm{kg}$ ) and $600 \mathrm{MPa}(0.9 \mathrm{mg} \mathrm{MDA} / \mathrm{kg})$, followed by flat cut (Figure 1B-f) at $600 \mathrm{MPa}$ $(0.8 \mathrm{mg} \mathrm{MDA} / \mathrm{kg})$, heel cut (Figure 1B-h) at $600 \mathrm{MPa}(0.54 \mathrm{mg} \mathrm{MDA} / \mathrm{kg})$, and tenderloin cut (Figure 1B-d) at $400 \mathrm{MPa}(0.63 \mathrm{mg} \mathrm{MDA} / \mathrm{kg})$ and $600 \mathrm{MPa}(0.57 \mathrm{mg} \mathrm{MDA} / \mathrm{kg})$. Similarly, McArdle et al. [18] reported a significant increase in TBARS values of lamb brisket cut (M. pectoralis profundus muscle) after 30 days' storage with increased pressures $\left(200,400\right.$ and $600 \mathrm{MPa}$ at $\left.60^{\circ} \mathrm{C}\right)$ during high-pressure treatment. Ma et al. [9] reported that the TBARS value of beef muscle (stored for 7 days at $4{ }^{\circ} \mathrm{C}$ and treated at $\left.20^{\circ} \mathrm{C}\right)$ was significantly the highest at $400 \mathrm{MPa}(0.67 \mathrm{mg} \mathrm{MDA} / \mathrm{kg})$, which then decreased at $600 \mathrm{MPa}$ $(0.52 \mathrm{mg} \mathrm{MDA} / \mathrm{kg})$ and $800 \mathrm{MPa}(0.41 \mathrm{mg} \mathrm{MDA} / \mathrm{kg})$. Only knuckle cut (Figure 1B-c) in this study had a TBARS value of above $0.5 \mathrm{mg} \mathrm{MDA} / \mathrm{kg}$ at $300 \mathrm{MPa}(0.52 \mathrm{mg} \mathrm{MDA} / \mathrm{kg})$. In general, when higher levels of pressure (400 and $600 \mathrm{MPa}$ ) were employed, it resulted in higher oxidation values exceeding $0.5 \mathrm{mg} \mathrm{MDA} / \mathrm{kg}$ in eye of loin (Figure 1B-e), flat (Figure 1B-f), heel (Figure 1B-h) and tenderloin (Figure 1B-d) cuts, except for knuckle cut (Figure 1B-c) that had the highest oxidation value at $300 \mathrm{MPa}$. On the other hand, lower pressures of 200 and / or 300 MPa resulted in oxidation values less than $0.5 \mathrm{mg} \mathrm{MDA} / \mathrm{kg}$ for all cuts. In previous studies [6,9], elevated pressures at room temperature decreased the oxidative stability of red meat. The pressures required to initiate these changes were lower for beef (200 MPa), compared to pork (300 MPa) and chicken (600 MPa), although the postslaughter history of the samples varied [9]. It has been postulated that this phenomenon is due to the release of "free" iron from the iron complexes present in meat. As the concentration of "free" iron increased in red meat samples after pressure treatments [9,10], chelating agents (such as EDTA) effectively prevented the increased rates of oxidation seen in pressure-treated pork [6]. It is also possible that the effects of pressure may be related to changes in the integrity of the cell membrane [8].

\subsection{Fatty Acids}

\subsubsection{Fatty Acid Composition in Different Control Cuts}

In this study, the fatty acid composition of saturated, monounsaturated, and polyunsaturated fatty acids in selected New Zealand lamb meat cuts is summarised in Table 1. The results in this study were similar to the fatty acid composition of other livestock species reared for meat production [30]. C16:0 palmitic acid and C18:0 stearic acid are usually the major saturated fatty acids in lamb meat and lamb meat products [35], and this was in agreement with our results for all cuts. Saturated fatty acids present in this study included C16:0, C17:0, C18:0, C20:0, C22:0 and C23:0 (Table 1). These fatty acids, except for C23:0, were significantly higher in the bolar cut, followed by the eye of loin, knuckle, tenderloin, and flat cuts. Similarly, Rhee et al. [31] who analysed the fatty acid composition of beef rump, tenderloin, inside and heel cuts, showed that C18:0 fatty acid in the tenderloin cut was significantly higher compared to rump, inside and heel cuts. Badiani et al. [32] analysed fresh and cooked beef bolar, flat and heel cuts, and reported that bolar cut contained the highest level of fatty acids compared to flat and heel cuts. In addition, the value of total saturated fatty acids in the bolar cut was about two times more than in flat and heel cuts in their study, which was similar to the results of this study. 
Table 1. Fatty acid composition $(\mathrm{mg} / 100 \mathrm{~g})$ in different New Zealand lamb meat cuts.

\begin{tabular}{|c|c|c|c|c|c|c|c|c|c|}
\hline $\begin{array}{c}\text { Fatty } \\
\text { Acids/Cuts }\end{array}$ & Bolar & Eye of Loin & Flat & Heel & Inside & Knuckle & Rump & Tenderloin & $p$-Value \\
\hline C16:0 & $14.96 \pm 0.03^{a}$ & $14.08 \pm 0.09^{b}$ & $8.02 \pm 0.61^{\mathrm{d}}$ & $5.14 \pm 0.11^{\mathrm{e}}$ & $3.8 \pm 0.16^{f}$ & $10.53 \pm 0.02^{c}$ & $4.5 \pm 0.44^{\mathrm{e}}$ & $10.84 \pm 0.29^{c}$ & $* * * *$ \\
\hline $\mathrm{C} 16: 1$ & $0.77 \pm 0.03^{b}$ & $0.9 \pm 0.01^{\mathrm{a}}$ & $0.56 \pm 0.05^{\mathrm{e}}$ & $0.39 \pm 0.02^{f}$ & $0.31 \pm 0.01^{\mathrm{g}}$ & $0.62 \pm 0.01^{\mathrm{d}}$ & $0.35 \pm 0.02 \mathrm{fg}$ & $0.71 \pm 0.00^{c}$ & $* * * *$ \\
\hline C17:0 & $1.06 \pm 0.00^{\mathrm{a}}$ & $0.82 \pm 0.01^{b}$ & $0.44 \pm 0.04^{\mathrm{e}}$ & $0.35 \pm 0.01^{\mathrm{f}}$ & $0.27 \pm 0.00^{g}$ & $0.67 \pm 0.01^{\mathrm{d}}$ & $0.32 \pm 0.00^{f}$ & $0.73 \pm 0.05^{c}$ & $* * * *$ \\
\hline $\mathrm{C} 17: 1$ & $0.48 \pm 0.00^{\mathrm{a}}$ & $0.46 \pm 0.01^{a}$ & $0.31 \pm 0.01^{\mathrm{cd}}$ & $0.25 \pm 0.00 \mathrm{de}$ & $0.21 \pm 0.01 \mathrm{e}^{\mathrm{e}}$ & $0.37 \pm 0.01^{b c}$ & $0.22 \pm 0.011^{\mathrm{e}}$ & $0.41 \pm 0.09^{a b}$ & $* * * *$ \\
\hline C18:0 & $15.86 \pm 0.21^{\mathrm{a}}$ & $11.33 \pm 0.06^{b c}$ & $5.58 \pm 0.59 \mathrm{~d}$ & $4.63 \pm 0.15^{\mathrm{e}}$ & $3.2 \pm 0.23^{f}$ & $10.86 \pm 0.05^{c}$ & $4.58 \pm 0.17^{\mathrm{e}}$ & $11.63 \pm 0.18^{b}$ & $* * * *$ \\
\hline $18: \ln 9$ & $16.29 \pm 0.03^{b}$ & $20.28 \pm 0.12^{a}$ & $12.77 \pm 0.69^{d}$ & $8.27 \pm 0.3^{\mathrm{e}}$ & $6.13 \pm 0.26^{f}$ & $14.53 \pm 0.05^{c}$ & $6.89 \pm 0.72^{f}$ & $16.29 \pm 0.5^{b}$ & $* * * *$ \\
\hline $18: 2 \mathrm{n} 6$ & $2.6 \pm 0.09 \mathrm{de}$ & $3.48 \pm 0.22^{c}$ & $2.28 \pm 0.27^{\mathrm{e}}$ & $2.78 \pm 0.1^{d}$ & $2.43 \pm 0.22 \mathrm{de}$ & $3.96 \pm 0.03^{b}$ & $3.19 \pm 0.07^{c}$ & $5.64 \pm 0.15^{a}$ & $* * * *$ \\
\hline $18: 3 n 6$ & $0.68 \pm 0.03^{a}$ & $0.49 \pm 0.06^{b}$ & $0.21 \pm 0.05^{c}$ & $0.23 \pm 0.00^{c}$ & $0.15 \pm 0.04^{c}$ & $0.39 \pm 0.02^{b}$ & $0.24 \pm 0.05^{c}$ & $0.4 \pm 0.08^{b}$ & $* * * *$ \\
\hline $18: 3 n 3$ & $1.29 \pm 0.02^{b}$ & $1.1 \pm 0.02^{\mathrm{c}}$ & $0.72 \pm 0.03$ de & $0.71 \pm 0.00^{\mathrm{e}}$ & $0.64 \pm 0.03^{f}$ & $1.12 \pm 0.01^{\mathrm{c}}$ & $0.76 \pm 0.03^{\mathrm{d}}$ & $1.38 \pm 0.02^{\mathrm{a}}$ & $* * * *$ \\
\hline $\mathrm{C} 20: 0$ & $0.53 \pm 0.02^{a}$ & $0.41 \pm 0.02^{b}$ & $0.27 \pm 0.03^{c}$ & $0.26 \pm 0.03^{c}$ & $0.24 \pm 0.01^{c}$ & $0.39 \pm 0.01^{b}$ & $0.28 \pm 0.02^{c}$ & $0.41 \pm 0.01^{b}$ & $* * * *$ \\
\hline $20: 4 n 6$ & $0.25 \pm 0.00$ & $0.28 \pm 0.09$ & $0.35 \pm 0.12$ & $0.37 \pm 0.09$ & $0.41 \pm 0.01$ & $0.41 \pm 0.02$ & $0.45 \pm 0.01$ & $0.44 \pm 0.05$ & ns \\
\hline $20: 5 n 3$ & $0.18 \pm 0.00^{\mathrm{d}}$ & $0.27 \pm 0.00^{c}$ & $0.32 \pm 0.03^{a b}$ & $0.33 \pm 0.00^{\mathrm{ab}}$ & $0.33 \pm 0.03^{a b}$ & $0.31 \pm 0.01^{b}$ & $0.34 \pm 0.00^{\mathrm{ab}}$ & $0.34 \pm 0.01^{\mathrm{a}}$ & $* * * *$ \\
\hline $\mathrm{C} 22: 0$ & $0.24 \pm 0.01$ & $0.2 \pm 0.01$ & $0.19 \pm 0.02$ & $0.18 \pm 0.00$ & $0.17 \pm 0.00$ & $0.22 \pm 0.01$ & $0.19 \pm 0.00$ & $0.23 \pm 0.05$ & ns \\
\hline $22: 2 n 6$ & $0.39 \pm 0.01^{\mathrm{a}}$ & $0.32 \pm 0.01^{b}$ & $0.21 \pm 0.05^{\text {cde }}$ & $0.2 \pm 0.03$ de & $0.14 \pm 0.01^{\mathrm{f}}$ & $0.26 \pm 0.02^{c}$ & $0.19 \pm 0.02$ ef & $0.25 \pm 0.01^{\mathrm{cd}}$ & $* * * *$ \\
\hline C23:0 & $0.2 \pm 0.00$ & $0.1 \pm 0.18$ & $0.12 \pm 0.12$ & $0.12 \pm 0.02$ & $0.14 \pm 0.00$ & $0.24 \pm 0.03$ & $0.23 \pm 0.00$ & $0.1 \pm 0.08$ & ns \\
\hline SFA & $32.85 \pm 0.21^{\mathrm{a}}$ & $26.92 \pm 0.33^{b}$ & $14.62 \pm 1.4^{\mathrm{d}}$ & $10.69 \pm 0.31^{\mathrm{e}}$ & $7.82 \pm 0.40^{f}$ & $22.91 \pm 0.07^{\mathrm{c}}$ & $10.09 \pm 0.63^{\mathrm{e}}$ & $23.94 \pm 0.55^{c}$ & $* * * *$ \\
\hline MUFA & $17.53 \pm 0.00^{b}$ & $21.65 \pm 0.10^{\mathrm{a}}$ & $13.64 \pm 0.75^{\mathrm{d}}$ & $8.91 \pm 0.32 \mathrm{e}$ & $6.65 \pm 0.28^{f}$ & $15.53 \pm 0.05^{c}$ & $7.45 \pm 0.75^{\mathrm{f}}$ & $17.4 \pm 0.59^{b}$ & $* * * *$ \\
\hline PUFA & $5.4 \pm 0.15^{\mathrm{cd}}$ & $5.93 \pm 0.35 \mathrm{bc}$ & $4.09 \pm 0.54^{\mathrm{f}}$ & $4.62 \pm 0.22$ ef & $4.1 \pm 0.26^{\mathrm{f}}$ & $6.46 \pm 0.05^{b}$ & $5.16 \pm 0.07 \mathrm{de}$ & $8.45 \pm 0.32^{a}$ & $* * * *$ \\
\hline$n-3$ & $1.48 \pm 0.02^{b}$ & $1.36 \pm 0.02^{c}$ & $1.04 \pm 0.05^{\mathrm{d}}$ & $1.04 \pm 0.00^{\mathrm{d}}$ & $0.97 \pm 0.01^{\mathrm{e}}$ & $1.43 \pm 0.00^{b}$ & $1.1 \pm 0.03^{\mathrm{d}}$ & $1.73 \pm 0.03^{\mathrm{a}}$ & $* * * *$ \\
\hline$n-6$ & $3.92 \pm 0.13^{\mathrm{d}}$ & $4.57 \pm 0.37^{b c}$ & $3.04 \pm 0.49 \mathrm{e}$ & $3.58 \pm 0.22$ de & $3.13 \pm 0.26^{\mathrm{e}}$ & $5.03 \pm 0.05^{b}$ & $4.06 \pm 0.10^{\mathrm{cd}}$ & $6.73 \pm 0.29^{a}$ & $* * * *$ \\
\hline PUFA/SFA & $0.16 \pm 0.00^{f}$ & $0.22 \pm 0.02 \mathrm{e}^{\mathrm{e}}$ & $0.28 \pm 0.01^{\mathrm{d}}$ & $0.43 \pm 0.01^{b}$ & $0.53 \pm 0.01^{\mathrm{a}}$ & $0.28 \pm 0.00^{\mathrm{d}}$ & $0.51 \pm 0.01^{\mathrm{a}}$ & $0.35 \pm 0.01^{c}$ & $* * * *$ \\
\hline n6:n3 & $2.65 \pm 0.02^{d}$ & $3.35 \pm 0.41 \mathrm{bc}$ & $2.92 \pm 0.21^{\mathrm{cd}}$ & $3.43 \pm 0.22 \mathrm{ab}$ & $3.22 \pm 0.23 b c$ & $3.5 \pm 0.05^{\mathrm{ab}}$ & $3.7 \pm 0.15^{a b}$ & $3.9 \pm 0.14^{\mathrm{a}}$ & $* * *$ \\
\hline total & $55.77 \pm 0.36^{a}$ & $54.5 \pm 0.78^{a}$ & $32.34 \pm 2.7^{\mathrm{d}}$ & $24.21 \pm 0.85^{\mathrm{e}}$ & $18.57 \pm 0.94^{\mathrm{f}}$ & $44.9 \pm 0.03^{c}$ & $22.71 \pm 1.31^{\mathrm{e}}$ & $49.79 \pm 1.46^{b}$ & $* * * *$ \\
\hline
\end{tabular}

Values with different superscripts $(\mathrm{a}, \mathrm{b}, \mathrm{c}, \mathrm{d}, \mathrm{e}, \mathrm{f})$ in the same row differ significantly within cuts. SFA stands for saturated fatty acids; MUFA stands for monounsaturated fatty acids; PUFA

stands for polyunsaturated fatty acids. $p<0.0001$ is presented as $* * * *$ for level of significance; $p<0.001$ is presented as *** for level of significance; ns means not statistically significant. 
The monounsaturated fatty acids in this project were C16:1, C17:1 and C18:1n-9. Kelly et al. [35] reported that oleic $\mathrm{C} 18: 1$ was the most abundant monounsaturated fatty acid in meat products, similar to this study. The eye of loin cut had the highest level of C16:1, C17:1, C18:1n-9, and total monounsaturated fatty acids. Inside and rump cuts had a lower amount of C16:1, C17:1, and C18:1n-9 fatty acid and total monounsaturated fatty acid content compared to other cuts. Similarly, Badiani et al. [32] analysed fresh and cooked beef bolar, flat and heel cuts. They found that the monounsaturated fatty acids in the bolar cut were significantly higher than flat and heel cuts.

The polyunsaturated fatty acids reported in this study included 18:2n-6, 18:3n-6, 18:3n-3, 20:4n-6, 20:5n-3 and 22:2n-6 fatty acids. Kelly et al. [35] reported that linoleic C18:2 was the major unsaturated fatty acid in meat products, similar to this study for all cuts. Generally, tenderloin cut had the highest level of PUFAs. Lower but significant levels of PUFAs were present in flat, heel and inside cuts. Similarly, Manner et al. [36] reported significantly higher levels of C18:2 in the tenderloin cut than the heel cut in steers. Badiani et al. [32] also reported that total PUFAs in the beef bolar cut were significantly higher than flat and heel cuts. However, Rhee et al. [31] found no significant differences in PUFA levels in inside, heel, rump, and tenderloin cuts of porcine meat.

According to Wood et al. [30], the polyunsaturated/saturated fatty acid (PUFA/SFA) ratios for lamb are typically 0.1 but can be higher in some muscles. A higher PUFA to SFA ratio $(\geq 0.4)$ is desirable as it decreases the risks of cardiovascular disease and metabolic syndrome [37]. Factors that affect this ratio include animal breed, sex and nutrition [38]. Our results showed that the PUFA/SFA ratios of heel (0.43), inside (0.53) and rump (0.51) cuts were higher than 0.4. The ratio of omega- 6 to omega-3 PUFAs (n6: n3) shown in Table 1 is also important as it is a risk factor in cancer and coronary heart diseases [38]. The recommendation is for a ratio of less than 4 [30]. The n6:n3 ratios in this study ranged from 2.65 to 3.90 for all samples, which fall within the recommended ratio.

\subsubsection{Effect of Different HPP Treatments on Fatty Acid Composition}

HPP-treated rump and heel cuts had significantly higher SFA and MUFA contents, as well as significantly lower PUFA/SFA ratios compared to control samples (Table S1). As palmitic acid (C16:0) and stearic acid (C18:0) are the most abundant SFAs, the increase in SFAs is likely to be attributed to these fatty acids $[39,40]$ while the significant increase in MUFAs is likely to be associated with a significant increase of C18:1n-9 since lamb meat has been reported to contain more oleic acid, C18:1n-9 [41,42]. Similarly, in terms of cuts, Ma et al. [40] reported that the shoulder cut of lamb had significantly higher MUFA content compared to the loin cut. This increase was also attributed to the increase in C18:1n-9 fatty acid. PUFA content was not significantly different to control for both cuts, suggesting that little or no oxidation occurred [43]. This is supported by the oxidation results in this study for rump and heel cuts, which reached a maximum of 0.448 and $0.541 \mathrm{mg} \mathrm{MDA} / \mathrm{kg}$, respectively, at $600 \mathrm{MPa}$.

SFA and MUFA content were significantly lower in HPP-treated inside, bolar, knuckle, eye of loin, tenderloin and flat cuts at all pressures compared to control samples. PUFA content was also lower in HPP-treated inside (all pressures), knuckle (400 and $600 \mathrm{MPa}$ ), eye of loin (300 MPa) and tenderloin (600 MPa) cuts compared to control. Similarly, Yang et al. [44] found that total SFA, MUFA and PUFA content significantly decreased during HPP treatment of marinated pork meat compared to control. He et al. [45] also found that the percentage of SFA and MUFA significantly decreased after HPP treatment (350 and $500 \mathrm{MPa}$ ) of pork and subsequent storage. Yang et al. [46] reported a significant decrease in PUFA in dry-cured ham in the first 4 months of aging. With respect to individual fatty acids, a significant decrease in PUFAs at high pressure was mainly associated with changes in C18:2n-6 and C18:3n-3. Similarly, Ma et al. [40] found that total PUFA content was significantly lower at 200 and $300 \mathrm{MPa}$ in shank and shoulder cuts of lamb compared to control samples. The authors associated this decrease in PUFA content with changes in C18:2n-6 and C18:3n-3 fatty acid content. Oxidation of long-chain fatty acids is slower, with unsaturated fatty acids being oxidized more rapidly than saturated fatty acids [47]. In this study, as pressure increased, lipid oxidation levels also increased. 
Shahidi and Zhong [28] demonstrated that PUFAs in meat can react with molecular oxygen through a free radical chain mechanism to form fatty acyl hydroperoxides and other primary oxidation products. In addition, Wood et al. [30] indicated that oxidative stability PUFAs is affected by the composition of fatty acids during processing, ageing and retail display. Pereda et al. [48] further showed that fatty acids can decrease as a result of fatty acid oxidation and acidification, thereby supporting the decrease in fatty acid content in this study.

As mentioned before, the recommended PUFA/SFA ratio should be above 0.4 [30]. The PUFA/SFA ratios for different muscles ranged from 0.16 to 0.49 in goat meat, according to Banskalieva et al. [12]. Tshabalala et al. [49] further reported PUFA/ SFA ratios of 0.62 to 0.79 in goat meat. In this study, HPP-treated inside (at all pressures), knuckle (300 and $400 \mathrm{MPa})$, eye of loin (300 MPa), tenderloin (400 MPa) and flat (all pressures) muscles had PUFA/SFA ratios of more than 0.4 compared to control samples. Hence, HPP processing in this study resulted in a positive effect on PUFA/SFA ratios of some lamb cuts. Furthermore, the n:6/n:3 PUFA ratios of all samples in this study remained within the recommended level of $\leq 4$ [38]. Similarly, McArdle et al. [18] reported that high pressure had no significant effect on $\mathrm{n} 6: \mathrm{n} 3$ ratios in lamb meat.

\subsection{Free Amino Acids}

\subsubsection{Free Amino Acid Content of Different Control Cuts}

In this study, seventeen amino acids (alanine, glycine, valine, leucine, threonine, serine, isoleucine, proline, aspartic acid, methionine, glutamic acid, phenylalanine, ornithine, lysine, histidine, tyrosine, tryptophan) were identified and quantified. The results are given as mean values $(\mathrm{mg} / 100 \mathrm{~g})$ of free amino acids, as shown in Table 2. The presence of cysteine (CYS) and arginine (ARG) have been previously reported in raw goat meat at 0.01 and $12.2 \mathrm{mg} / 100 \mathrm{~g}$, respectively [50], which are quite low values. However, these free amino acids were not identified in the current study due to the limitations of the amino acid analysis kit used (Phenomenex, 2003), as reported in another study [51].

Nine essential free amino acids (valine, leucine, isoleucine, methionine, phenylalanine, lysine, histidine, tyrosine and tryptophan), and eight non-essential free amino acids (alanine, glycine, threonine, serine, proline, aspartic acid, glutamic acids and ornithine) were detected. In general, the type of cut had a significant effect on the free amino acid composition. Table 2 showed that the total amount of free amino acids in the inside cut was significantly higher for almost all individual free amino acids except for proline, glutamic acid and methionine. Bolar, eye of loin, heel, knuckle, rump and tenderloin cuts, on the other hand, had significantly lower total free amino acids. Generally, our results showed that alanine, glycine, glutamic and aspartic acid are the major non-essential amino acids. Valine and leucine were the major essential amino acids in this study. Similarly, Hollo et al. [52] reported that the highest essential amino acid fractions in beef were lysine and leucine.

\subsubsection{Non-essential Free Amino Acid Content in Different Control Cuts}

The major non-essential free amino acids found were alanine, glycine, glutamic acid and aspartic acid (Table 2). Madruga et al. [50] reported that the most abundant free amino acids in the rump of goat meat were glycine, alanine, and glutamine. Watanabe et al. [53] reported that alanine, glutamic acid and aspartic acid were the major amino acids in cattle. In addition, Holló et al. [52] reported that the major non-essential amino acids in beef were glutamic acid and aspartic acid. The eight non-essential free amino acids (alanine, glycine, threonine, serine, proline, aspartic acid, glutamic acids and ornithine) found in this study accounted for approximately $70 \%$ to $80 \%$ of the total amino acids. 
Table 2. Free amino acid composition $(\mathrm{mg} / 100 \mathrm{~g})$ in different New Zealand lamb meat cuts.

\begin{tabular}{|c|c|c|c|c|c|c|c|c|c|}
\hline Cuts & Bolar & Eye of Loin & Flat & Heel & Inside & Knuckle & Rump & Tenderloin & $p$-Value \\
\hline \multicolumn{10}{|l|}{ Nonessential } \\
\hline Alanine & $62.79 \pm 0.67^{c}$ & $54.85 \pm 2.14^{\mathrm{cd}}$ & $54.3 \pm 2.36^{\mathrm{d}}$ & $78.25 \pm 8.27^{b}$ & $92.89 \pm 2.81^{\mathrm{a}}$ & $58.54 \pm 0.11^{\mathrm{cd}}$ & $78.65 \pm 2.48^{\mathrm{b}}$ & $72.75 \pm 3.61^{b}$ & $* * * *$ \\
\hline Glycine & $60.45 \pm 2.37^{\mathrm{a}}$ & $44.74 \pm 3.95^{c}$ & $49.97 \pm 2.63^{\mathrm{bc}}$ & $49.7 \pm 1.32^{\mathrm{bc}}$ & $59.44 \pm 4.61^{\mathrm{a}}$ & $44.58 \pm 1.37^{\mathrm{c}}$ & $54.69 \pm 4.37^{\mathrm{ab}}$ & $43.82 \pm 1.59^{c}$ & $* *$ \\
\hline Serine & $12.91 \pm 2.67^{\mathrm{C}}$ & $17.12 \pm 4.37^{\mathrm{bc}}$ & $26.01 \pm 1.39^{a}$ & $17.92 \pm 4.96^{\mathrm{bc}}$ & $26.26 \pm 4.74^{\mathrm{a}}$ & $12.41 \pm 2.16^{\mathrm{c}}$ & $18.28 \pm 2.8^{\mathrm{bc}}$ & $21.2 \pm 0.22^{\mathrm{ab}}$ & * \\
\hline Threonine & $11.93 \pm 1.49^{c}$ & $15.54 \pm 6.92^{\mathrm{bc}}$ & $27.05 \pm 0.75^{\mathrm{a}}$ & $15.31 \pm 2.49^{b c}$ & $28.76 \pm 1.06^{\mathrm{a}}$ & $15.4 \pm 0.85 b^{c}$ & $18.98 \pm 0.14^{\mathrm{b}}$ & $17.6 \pm 0.16^{\mathrm{bc}}$ & $* *$ \\
\hline Proline & $9.94 \pm 1.42$ & $8.08 \pm 1.65$ & $12.12 \pm 2.57$ & $5.84 \pm 1.1$ & $7.44 \pm 0.34$ & $6.12 \pm 1.52 b$ & $8.7 \pm 3.24$ & $3.1 \pm 0.85$ & ns \\
\hline Glutamic acid & $63.57 \pm 6.65^{\mathrm{bc}}$ & $54.66 \pm 0.13^{c}$ & $82.66 \pm 4.75^{\mathrm{a}}$ & $78.02 \pm 18.46^{\mathrm{ab}}$ & $56.76 \pm 3.68^{c}$ & $82.16 \pm 6.19^{a}$ & $35.35 \pm 2.89^{\mathrm{d}}$ & $48.44 \pm 1.71^{\mathrm{cd}}$ & $* *$ \\
\hline Aspartic acid & $122.33 \pm 1.89^{a b}$ & $114.73 \pm 1.5^{\mathrm{abc}}$ & $129.87 \pm 2.86^{\mathrm{a}}$ & $100.96 \pm 19.5^{\mathrm{cd}}$ & $118.98 \pm 1.37^{a b c}$ & $105.54 \pm 3.07^{\mathrm{bcd}}$ & $71.06 \pm 9.71^{\mathrm{e}}$ & $89.32 \pm 1.37^{\mathrm{de}}$ & $* * *$ \\
\hline Ornithine & $4.93 \pm 0.06$ & $5.94 \pm 1.29$ & $6.02 \pm 0.76$ & $4.94 \pm 0.05$ & $5.33 \pm 0.97$ & $5.45 \pm 0.1$ & $7.35 \pm 2.19$ & $4.51 \pm 0.07$ & ns \\
\hline NEAA & $348.85 \pm 6.75^{\mathrm{bc}}$ & $315.66 \pm 10.63^{\text {cde }}$ & $387.99 \pm 4.6^{\mathrm{a}}$ & $350.96 \pm 38.51^{b}$ & $395.87 \pm 2.88^{\mathrm{a}}$ & $330.21 \pm 9.24^{\mathrm{bcd}}$ & $293.05 \pm 3.16^{\mathrm{e}}$ & $300.73 \pm 0.24^{\mathrm{de}}$ & $* * *$ \\
\hline \multicolumn{10}{|l|}{ Essential } \\
\hline Valine & $13.85 \pm 0.47^{\mathrm{c}}$ & $19.61 \pm 8.64^{b c}$ & $26.05 \pm 4.4^{\mathrm{b}}$ & $19.77 \pm 0.1^{\mathrm{bc}}$ & $38.01 \pm 1.34^{\mathrm{a}}$ & $18.67 \pm 4.22^{\mathrm{bc}}$ & $19.12 \pm 1.21^{b c}$ & $16.88 \pm 1.13^{c}$ & $* *$ \\
\hline Leucine & $12.07 \pm 0.58^{\mathrm{cd}}$ & $10.71 \pm 0.97^{\mathrm{d}}$ & $15.29 \pm 0.67^{\mathrm{bc}}$ & $13.68 \pm 2.05^{\mathrm{bcd}}$ & $27.67 \pm 1.84^{\mathrm{a}}$ & $15.2 \pm 3.33^{\mathrm{bc}}$ & $16.71 \pm 0.95^{\mathrm{b}}$ & $14.06 \pm 0.5^{\mathrm{bcd}}$ & $* * * *$ \\
\hline Isoleucine & $7.8 \pm 0.28^{\mathrm{e}}$ & $10.58 \pm 2.46^{\mathrm{de}}$ & $16.87 \pm 0.66^{\mathrm{b}}$ & $13.15 \pm 1.95^{\mathrm{bcd}}$ & $23.36 \pm 0.5^{\mathrm{a}}$ & $15.44 \pm 1.87^{\mathrm{bc}}$ & $23 \pm 2.65^{\mathrm{a}}$ & $12 \pm 0.69^{\mathrm{cd}}$ & $* * * *$ \\
\hline Methionine & $4.67 \pm 0.32^{\mathrm{d}}$ & $4.95 \pm 1.01^{\mathrm{d}}$ & $4.11 \pm 0.94^{\mathrm{d}}$ & $3.53 \pm 0.65^{\mathrm{d}}$ & $9.38 \pm 0.24^{\mathrm{b}}$ & $6.96 \pm 1.33^{c}$ & $14.78 \pm 0.48^{\mathrm{a}}$ & $4.74 \pm 0.42^{\mathrm{d}}$ & $* * * *$ \\
\hline Phenylalanine & $13.05 \pm 1.49^{\text {cde }}$ & $10.13 \pm 1.5^{\mathrm{e}}$ & $11.55 \pm 0.23^{\mathrm{de}}$ & $16.61 \pm 1.94^{\mathrm{ab}}$ & $19.91 \pm 0.75^{\mathrm{a}}$ & $13.1 \pm 2.11^{\text {cde }}$ & $14.8 \pm 1.09^{\mathrm{bcd}}$ & $15.4 \pm 1.54^{\mathrm{bc}}$ & $* *$ \\
\hline Lysine & $8.26 \pm 0.26$ & $10.25 \pm 1.61$ & $9.62 \pm 0.66$ & $8.67 \pm 0.97$ & $9.51 \pm 0.41$ & $8.24 \pm 0.59$ & $9.29 \pm 0.33$ & $10.97 \pm 0.12$ & ns \\
\hline Histidine & $13.67 \pm 0.75$ & $10.64 \pm 0.25$ & $13.24 \pm 0.42$ & $11.81 \pm 1.27$ & $12.57 \pm 1.38$ & $12.66 \pm 1.13$ & $11.87 \pm 0.23$ & $12.9 \pm 1.35$ & ns \\
\hline Tyrosine & $10.43 \pm 1.44^{\mathrm{b}}$ & $16.98 \pm 2.4^{\mathrm{a}}$ & $11.23 \pm 0.5^{b}$ & $9.14 \pm 1.08^{b}$ & $17.12 \pm 0.71^{\mathrm{a}}$ & $11.27 \pm 2.58^{\mathrm{b}}$ & $11.5 \pm 2.62^{\mathrm{b}}$ & $15.54 \pm 0.78^{\mathrm{a}}$ & $* *$ \\
\hline Tryptophan & $5.68 \pm 0.51^{d}$ & $8.03 \pm 0.51^{\mathrm{ab}}$ & $6.24 \pm 0.6^{\mathrm{cd}}$ & $5.17 \pm 0.77^{d}$ & $8.63 \pm 0.02^{\mathrm{a}}$ & $7.51 \pm 0.4^{\mathrm{ab}}$ & $7.16 \pm 0.07^{\mathrm{bc}}$ & $5.23 \pm 0.54^{\mathrm{d}}$ & $* * *$ \\
\hline EAA & $89.48 \pm 1.19^{d}$ & $101.88 \pm 9.49^{\mathrm{cd}}$ & $114.19 \pm 8.09^{\mathrm{bc}}$ & $101.52 \pm 6.87^{\mathrm{cd}}$ & $166.17 \pm 1.41^{\mathrm{a}}$ & $109.04 \pm 16.37^{\mathrm{bc}}$ & $128.22 \pm 6.62^{\mathrm{b}}$ & $107.71 \pm 7.08^{\mathrm{cd}}$ & $* * * *$ \\
\hline TOTAL & $438.33 \pm 7.95^{c}$ & $417.54 \pm 20.12^{\mathrm{c}}$ & $502.18 \pm 3.49^{b}$ & $452.48 \pm 45.39^{c}$ & $562.03 \pm 1.46^{\mathrm{a}}$ & $439.25 \pm 25.61^{\mathrm{c}}$ & $421.28 \pm 9.78^{c}$ & $408.44 \pm 7.32^{\mathrm{c}}$ & $* * *$ \\
\hline
\end{tabular}

Values with different superscripts $(\mathrm{a}, \mathrm{b}, \mathrm{c}, \mathrm{d}, \mathrm{e})$ in the same row differ significantly within cuts. EAA stands for essential free amino acids; NEAA stands for nonessential free amino acids. $p<0.0001$ is presented as $* * * *$ for $0.001 \%$ level of significance; $p<0.001$ is presented as $* * *$ for $0.01 \%$ level of significance; $p<0.01$ is presented as $* *$ for $1 \%$ level of significance; $p<0.05$ is presented as * for $5 \%$ level of significance; ns means not statistically significant. 
In inside and flat cuts, the total non-essential free amino acids values were significantly higher compared to other cuts. On the other hand, eye of loin, rump and tenderloin cuts had significantly lower total non-essential free amino acid content. In this study, the flat cut had a significantly higher level of glutamic acid, and the rump cut had a significantly lower level of glutamic acid content. Similarly, Aristoy and Toldrá [54] analysed the free amino acids in porcine skeletal muscle with different oxidative patterns and demonstrated that the content of non-essential free amino acids such as glutamic acid and proline, as well as total free amino acids in the trapezius muscles (flat), were significantly higher than in rump muscles.

Franco et al. [55] studied total amino acids and free amino acids in different beef muscles (heel, bolar, inside, eye of loin, masseter and cardiac muscles), and reported that glutamic acid was the highest in the heel cut compared to other cuts (bolar, inside, eye of loin), similar to this study. In fact, our result showed that the knuckle, flat and heel cuts had significantly higher glutamic acid content than other muscles (eye of loin, inside, bolar, tenderloin and rump). Franco et al. [55] also reported that aspartic acid was the major non-essential amino acid in all muscles (heel, bolar, inside, and eye of loin cuts). Similarly, aspartic acid was the major non-essential amino acid in this study, with significantly higher amounts in bolar, eye of loin, flat and inside cuts. Meanwhile, rump and tenderloin cuts had the lowest amount of aspartic acid in this study.

\subsubsection{Essential Free Amino Acids Content in Different Control Cuts}

In this study, nine essential free amino acids (valine, leucine, isoleucine, methionine, phenylalanine, lysine, histidine, tyrosine and tryptophan) accounted for $20 \%$ to $30 \%$ of total amino acids. The major essential amino acids found were valine, leucine, phenylalanine, tyrosine and histidine. Madruga et al. [50] reported that the most abundant essential free amino acids in the rump of goat meat were leucine and valine. As seen in Table 2, inside cut had significantly higher essential amino acids (EAAs), followed by the rump cut. Bolar, eye of loin, and heel cuts had the least EAA content.

There were significant differences in leucine, isoleucine and methionine content between cuts. Leucine content was highest in the inside cut $(27.67 \mathrm{mg} / 100 \mathrm{~g})$. However, bolar $(12.07 \mathrm{mg} / 100 \mathrm{~g})$, eye of loin $(10.71 \mathrm{mg} / 100 \mathrm{~g})$, heel $(12.68 \mathrm{mg} / 100 \mathrm{~g})$ and tenderloin $(14.06 \mathrm{mg} / 100 \mathrm{~g})$ cuts had significantly lower leucine content, similar to porcine rump cut $(19.15 \mathrm{mg} / 100 \mathrm{~g})$, as reported by Cornet and Bousset [56]. However, results in this study showed a higher leucine concentration for all cuts compared to Madruga et al. [50] (7.9 mg/100 $\mathrm{g}$ in raw goat rump cut) and Franco et al. [55] (beef heel $(6.00 \mathrm{mg} / 100 \mathrm{~g})$, bolar $(2.90 \mathrm{mg} / 100 \mathrm{~g})$, inside $(2.40 \mathrm{mg} / 100 \mathrm{~g})$, and eye of loin $(1.55 \mathrm{mg} / 100 \mathrm{~g}))$.

Isoleucine content was highest in inside $(23.36 \mathrm{mg} / 100 \mathrm{~g})$ and rump $(23.00 \mathrm{mg} / 100 \mathrm{~g})$ cuts. Similarly, Cornet and Bousset [56] reported $26.98 \mathrm{mg} / 100 \mathrm{~g}$ isoleucine in porcine rump cut. Bolar $(7.8 \mathrm{mg} / 100 \mathrm{~g}$ ) and eye of loin $(10.58 \mathrm{mg} / 100 \mathrm{~g})$ cuts had the lowest level of isoleucine content. These results were higher than reported by Franco et al. [55] for beef heel $(4.8 \mathrm{mg} / 100 \mathrm{~g})$, bolar $(5.02 \mathrm{mg} / 100 \mathrm{~g})$, inside $(5.55 \mathrm{mg} / 100 \mathrm{~g})$, and eye of loin $(2.61 \mathrm{mg} / 100 \mathrm{~g})$ cuts.

Methionine was only present at a very low concentration in this study. It was highest in the rump cut $(14.78 \mathrm{mg} / 100 \mathrm{~g})$. Bolar $(4.62 \mathrm{mg} / 100 \mathrm{~g})$, eye of loin $(4.95 \mathrm{mg} / 100 \mathrm{~g})$, flat $(4.11 \mathrm{mg} / 100 \mathrm{~g})$, heel $(3.53 \mathrm{mg} / 100 \mathrm{~g})$ and tenderloin $(4.74 \mathrm{mg} / 100 \mathrm{~g})$ cuts were present at significantly lower levels. These findings are similar to the methionine content reported by Cornet and Bousset [56], who reported $10.06 \mathrm{mg} / 100 \mathrm{~g}$ methionine in porcine rump cut, and Franco et al. [55], who reported $4.0 \mathrm{mg} / 100 \mathrm{~g}$ in beef heel cut, $1.55 \mathrm{mg} / 100 \mathrm{~g}$ in beef bolar cut, $1.77 \mathrm{mg} / 100 \mathrm{~g}$ in inside cut, and $0.87 \mathrm{mg} / 100 \mathrm{~g}$ in eye of loin cut. In other red meats, such as camel [57], hen [57] and ostrich [58], lysine was the major essential free amino acid. In our results, lysine was not significantly different between all cuts.

\subsubsection{Effect of Different HPP Treatments on Free Amino Acid Content}

The effect of high-pressure treatment on the free amino acid content is shown in Tables S2 and S3. Suzuki et al. [2] suggested that free amino acids have an important role in determining brothy and meaty flavours and that they are precursors of meat flavour. However, the effect of HPP on free amino 
acid content is not known. Campus et al. [22] studied free amino acids in dry-cured loins, and they showed that high pressure ( 300 to $400 \mathrm{MPa}$ for $10 \mathrm{~min}$ at $20^{\circ} \mathrm{C}$ ) can stabilize the free amino acid content during storage due to a reduction in the activity of amino peptidases. Moreover, Suzuki et al. [2] reported that high-pressure treatments (200 to $400 \mathrm{MPa}$ at ambient temperature) did not influence the amount of amino acids in beef shoulder skeletal muscles (heel).

As seen in Tables S2 and S3, HPP significantly increased the total free amino acid composition, compared to control, at all pressures for almost all cuts except the inside and eye of loin cuts. Many researchers have suggested that processing meat would increase the presence of certain free amino acids by proteolysis [54]. Most cuts had the highest levels of total amino acids at the $600 \mathrm{MPa}$ treatment except for the inside, eye of loin and tenderloin cuts. Total amino acids were significantly higher in the tenderloin cut at 200 and $400 \mathrm{MPa}$ and the inside cut at $200 \mathrm{MPa}$ compared to control. The increase in free amino acids was similarly reported by Ohmori et al. [21], who suggested that high pressure between 100 and $300 \mathrm{MPa}$ for $10 \mathrm{~min}$ at $25^{\circ} \mathrm{C}$ increases the overall autolytic activity of raw beef round (inside cut) meat and leads to a higher concentration of free amino acids. However, their results also showed that with higher pressure treatments at 400 and $500 \mathrm{MPa}$, the concentration of free amino acids was identical to that of the control sample, unlike results from this study.

As for the eye of loin cut, a significant decrease in total amino acids was observed at $600 \mathrm{MPa}$. In fact, there was a significant decrease in the essential amino acids leucine and isoleucine. Simonin et al. [20] suggested that muscle proteins are vulnerable to oxidative reactions that result in the loss of EAAs and a decrease in protein digestibility. The mechanisms and reaction pathways for lipid and protein oxidations are different, but they are directly linked; both processes may be affected by similar prooxidant and antioxidant factors. Indeed, it seems that protein oxidation is observed under the same pressure levels as those found when lipid oxidation occurs (>300 MPa). Results of lipid oxidation in this study support this and, in fact, the eye of loin cut had the highest level of lipid oxidation at $0.905 \mathrm{mg} \mathrm{MDA} / \mathrm{kg}$. In conclusion, our results showed that HPP processing of all cuts, except for eye of loin, generally increased the concentration of free amino acids. Further studies on the digestibility of meat [59] and HPP process optimisation to improve meat quality can contribute to the application of HPP in the real-life industrial processing of meat. Our study also promises the wider application of non-thermal processing technology. For example, the use of Pulsed Electric Field (PEF) in the seafood category [60].

\subsection{Multiple Factor Analysis on Fatty Acids, Free Amino Acid Content and TBARS}

Figure 2 illustrates the MFA plot showing the interrelationship between fatty acid, free amino acid and TBARS measures with varying HPP pressure treatments of different lamb meat cuts. Fatty acid and free amino acid scores showed an inverse relationship in this study. Most of the sample cuts were separated along the F1 axis, with $33.14 \%$ of variance explained. For most cuts (flat, heel, inside, knuckle, and rump), increasing HPP pressure treatments were associated with an increase in most free amino acids that had high positive loadings along the F1 axis. Previous literature has reported that dry-cured meat products can generate a large amount of small peptides and free amino acids, which can directly develop taste characteristics [61], aroma attributes and flavour precursors [62]. Koutsidis et al. [62] reported that free amino acids such as leucine, isoleucine, serine, threonine, valine, and phenylalanine may contribute to the brown/roasted attribute, which is desired by consumers. In a study by Herranz et al. [63], dry-fermented sausages treated with a $0.159 \%$ mixture of valine, leucine and isoleucine $(58 / 35 / 66 ; w / w)$ received the highest score for odour, flavour contribution and overall quality. Better flavour scores of the treated samples can be attributed to the higher concentration of volatile compounds that are derived from free amino acids, especially Ile, Leu, and Val. Similarly, Ma et al. [40] reported that lamb meat cuts treated with HPP at $400 \mathrm{MPa}$ had significantly higher His, Leu, Met, Lys, and Pro content, and samples treated with HPP at $600 \mathrm{MPa}$ were higher in Phe, Tyr, Gly, and Ile content compared to control. In another study by Yang et al. [64], HPP-treated (150 MPa) samples of marinated meat in soy sauce had a significantly higher concentration of glutamate and alanine 
than control, which contributed to the umami and sweet taste, respectively, that may further enhance the flavour of the meat. Although free amino acid content results in an increase in sensory quality, high levels of free amino acids, on the other hand, may result in decreased sensory acceptability of the product due to excessive proteolysis. In a study by Herranz et al. [63] samples treated with a $1.01 \%$ pool of 20 free amino acids (gly/asn/his/arg/thr/ala/pro/tyr/val/met/ile/leu/phe/trp/lys/asp/glu/ser/gln/cys) received lower scores for flavour compared to samples treated with $0.159 \%$ of amino acids (val/leu/ile), indicating that increased concentration of free amino acids may decrease the sensory quality of a product. The changes in chemical composition with HPP processing necessitate further work that investigates the sensory quality of the high-pressure-processed samples utilizing sensory temporal methods such as Temporal Dominance of Sensations [65] or Check-All-That Apply [66].

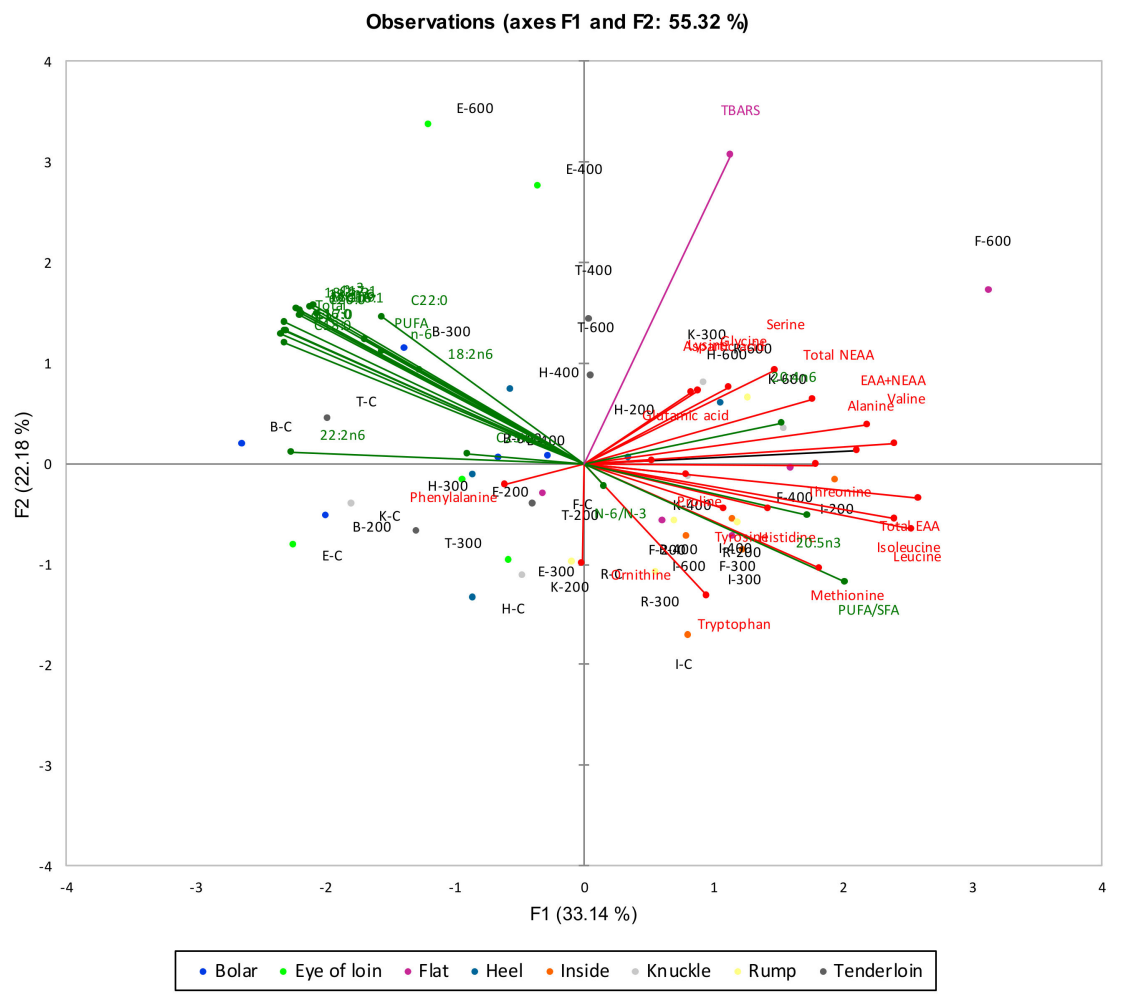

Figure 2. Multiple factor analysis (MFA) biplot for amino acids (red) and free fatty acids (green) for samples varying in cuts and HPP treatments. F1 (33.14\%) and F2 (22.18\%) explained a total of 55.32\% of the variance.

Control and low-pressure-treated bolar, eye of loin, and tenderloin lamb cuts were associated with an increase in most fatty acids that had high negative loadings along the F1 axis. Increased pressure treatments of these cuts were associated with a decrease in fatty acids that had low negative loadings along the F1 axis. Bolar, eye of loin and tenderloin cuts were significantly lower in SFA, MUFA, and PUFA content at higher pressure treatments, as compared to control (Table 1). A significant decrease in the fatty acids in the loin cut as compared to shank and shoulder cuts of lamb at higher pressures has also been observed by Ma et al. [40]. This reduction can be attributed to the increased oxidation and acidification of the fatty acids at higher pressures.

The tenderloin and eye of loin lamb cuts treated at high pressures of 400 and $600 \mathrm{MPa}$ were associated with higher TBARS values and separated from samples treated at 200 and $300 \mathrm{MPa}$ along the F2 axis, which accounted for $22.18 \%$ of the variance. Higher pressure treatments resulted in higher TBARS values in tenderloin and eye of loin lamb cuts, indicating their decreased oxidative stability. Park et al. [29] reported that pork loins had higher FFA (free fatty acid) values than belly meats, suggesting their increased oxidative susceptibility. Interestingly, tenderloin had a high PUFA 
content (Table 1), which makes it prone to lipolysis. Lipolysis has been regarded as a promoter of lipid oxidation due to the aggregation of fatty acids, particularly PUFAs, which are prone to lipid peroxidation [29]. All these findings resonate with the results described in Section 3.2.1.

Results from this study highlight that varying HPP treatments influenced the chemical composition of different lamb cuts. As these changes in chemical composition may affect the sensory qualities of various lamb cuts, further research is required to understand how HPP treatment can influence the sensory and flavour composition of HPP-treated lamb meat.

\section{Conclusions}

In this study, HPP treatments, varying in pressure, were applied to eight different lamb cuts in order to understand how important flavour indicators like lipid oxidation, fatty acid and free amino acid content were influenced. The results indicated that, in general, the eye of loin and tenderloin cuts treated at 400 and $600 \mathrm{MPa}$ and the flat and heel cuts treated at $600 \mathrm{MPa}$ are not suitable for the application of HPP. For most cuts, increasing the pressure of HPP treatments was associated with an increase in most of the free amino acids, a decrease in fatty acids, and higher TBARS values. The results from this study will be useful to the meat industry, with the increasing interest in the area of HPP to process meat products for export to the global market. It is important to note that in this study, a series of pilot tests of samples was used to determine the sampling method, using classical statistical inference (e.g., ANOVA). Hence, the limitation inherent to this approach is the lack of power calculation and understanding of effect sizes. We recommend future studies to utilize design of experiment approach to overcome the aforementioned statistical limitations [67].

Supplementary Materials: The following are available online at http://www.mdpi.com/2304-8158/9/10/1444/s1, Table S1: Fatty acid composition (g/100g dry meat) of New Zealand lamb cuts after HPP treatment, Table S2: The concentration of non-essential free amino acids composition $(\mathrm{mg} / 100 \mathrm{~g})$ of New Zealand lamb cuts subjected to different pressure treatments, Table S3: The concentration of essential free amino acids composition (mg/100g) of New Zealand lamb cuts subjected to different pressure treatments.

Author Contributions: Conceptualization, N.H. and I.O.; data curation, K.K., Y.C.W., and Q.M.; formal analysis, K.K., Y.C.W., and Q.M.; funding acquisition, N.H., I.O., and D.C.; investigation, Y.C.W. and Q.M.; methodology, N.H., I.O., and K.K.; project administration, N.H.; resources, M.F., and D.C.; supervision, N.H. and I.O.; validation, Q.M.; visualization, K.K., Y.C.W., and Q.M.; writing-original draft, K.K., N.H., I.O., Q.M., M.F., and D.C.; writing-review and editing, K.K. and N.H. All authors have read and agreed to the published version of the manuscript.

Funding: The Performance-Based Research Fund, Auckland University of Technology.

Acknowledgments: The authors would like to acknowledge the School of Sciences, Auckland University of Technology, for funding this research and Mustafa Farouk from AgResearch in New Zealand for providing samples for this research.

Conflicts of Interest: The authors have no conflicts of interest with the information shared in this article.

\section{References}

1. Kannan, G.; Kouakou, B.; Gelaye, S. Color changes reflecting myoglobin and lipid oxidation in chevon cuts during refrigerated display. Small Rumin. Res. 2001, 42, 67-74. [CrossRef]

2. Suzuki, A.; Homma, N.; Fukuda, A.; Hirao, K.; Uryu, T.; Ikeuchi, Y. Effects of high pressure treatment on the flavour-related components in meat. Meat Sci. 1994, 37, 369-379. [CrossRef]

3. Schmid, A. The Role of Meat Fat in the Human Diet. Crit. Rev. Food Sci. Nutr. 2010, 51, 50-66. [CrossRef] [PubMed]

4. Hugas, M.; Garriga, M.; Monfort, J. New mild technologies in meat processing: High pressure as a model technology. Meat Sci. 2002, 62, 359-371. [CrossRef]

5. Marcos, B.; Kerry, J.P.; Mullen, A.M. High pressure induced changes on sarcoplasmic protein fraction and quality indicators. Meat Sci. 2010, 85, 115-120. [CrossRef]

6. Cheah, P.; Ledward, D. High pressure effects on lipid oxidation in minced pork. Meat Sci. 1996, 43, 123-134. [CrossRef]

7. Angsupanich, K.; Ledward, D. High pressure treatment effects on cod (Gadus morhua) muscle. Food Chem. 1998, 63, 39-50. [CrossRef] 
8. Beltran, E.; Pla, R.; Yuste, J.; Mor-Mur, M. Lipid oxidation of pressurized and cooked chicken: Role of sodium chloride and mechanical processing on TBARS and hexanal values. Meat Sci. 2003, 64, 19-25. [CrossRef]

9. Ma, Q.; Hamid, N.; Oey, I.; Kantono, K.; Faridnia, F.; Yoo, M.; Farouk, M. Effect of chilled and freezing pre-treatments prior to pulsed electric field processing on volatile profile and sensory attributes of cooked lamb meats. Innov. Food Sci. Emerg. Technol. 2016, 37, 359-374. [CrossRef]

10. Wang, Q.; Zhao, X.; Ren, Y.; Fan, E.; Chang, H.; Wu, H. Effects of high pressure treatment and temperature on lipid oxidation and fatty acid composition of yak (Poephagus grunniens) body fat. Meat Sci. 2013, 94, 489-494. [CrossRef]

11. Orlien, V.; Hansen, E.; Skibsted, L.H. Lipid oxidation in high-pressure processed chicken breast muscle during chill storage: Critical working pressure in relation to oxidation mechanism. Eur. Food Res. Technol. 2000, 211, 99-104. [CrossRef]

12. Banskalieva, V.; Sahlu, T.; Goetsch, A. Fatty acid composition of goat muscles and fat depots: A review. Small Rumin. Res. 2000, 37, 255-268. [CrossRef]

13. Gerber, N.; Scheeder, M.R.L.; Wenk, C. The influence of cooking and fat trimming on the actual nutrient intake from meat. Meat Sci. 2009, 81, 148-154. [CrossRef] [PubMed]

14. Cruz-Romero, M.C.; Kerry, J.P.; Kelly, A.L. Fatty acids, volatile compounds and colour changes in high-pressure-treated oysters (Crassostrea gigas). Innov. Food Sci. Emerg. Technol. 2008, 9, 54-61. [CrossRef]

15. McArdle, R.; Marcos, B.; Kerry, J.P.; Mullen, A. Monitoring the effects of high pressure processing and temperature on selected beef quality attributes. Meat Sci. 2010, 86, 629-634. [CrossRef]

16. Yagiz, Y.; Kristinsson, H.G.; Balaban, M.O.; Welt, B.A.; Ralat, M.; Marshall, M.R. Effect of high pressure processing and cooking treatment on the quality of Atlantic salmon. Food Chem. 2009, 116, 828-835. [CrossRef]

17. Kang, G.; Cho, S.; Seong, P.; Park, B.; Kim, S.; Kim, D.; Kim, Y.; Kang, S.; Park, K. Effects of high pressure processing on fatty acid composition and volatile compounds in Korean native black goat meat. Meat Sci. 2013, 94, 495-499. [CrossRef]

18. McArdle, R.A.; Marcos, B.; Mullen, A.M.; Kerry, J.P. Influence of HPP conditions on selected lamb quality attributes and their stability during chilled storage. Innov. Food Sci. Emerg. Technol. 2013, 19, 66-72. [CrossRef]

19. Ono, K.; Berry, B.W.; Paroczay, E. Contents and Retention of Nutrients in Extra Lean, Lean and Regular Ground Beef. J. Food Sci. 1985, 50, 701-706. [CrossRef]

20. Simonin, H.; Duranton, F.; De Lamballerie, M. New Insights into the High-Pressure Processing of Meat and Meat Products. Compr. Rev. Food Sci. Food Saf. 2012, 11, 285-306. [CrossRef]

21. Ohmori, T.; Shigehisa, T.; Taji, S.; Hayashi, R. Effect of High Pressure on the Protease Activities in Meat. Agric. Biol. Chem. 1991, 55, 357-361.

22. Campus, M.; Flores, M.; Martinez, A.; Toldrá, F. Effect of high pressure treatment on colour, microbial and chemical characteristics of dry cured loin. Meat Sci. 2008, 80, 1174-1181. [CrossRef] [PubMed]

23. Nam, K.; Ahn, D. Use of antioxidants to reduce lipid oxidation and off-odor volatiles of irradiated pork homogenates and patties. Meat Sci. 2003, 63, 1-8. [CrossRef]

24. Faridnia, F.; Ma, Q.L.; Bremer, P.J.; Burritt, D.J.; Hamid, N.; Oey, I. Effect of freezing as pre-treatment prior to pulsed electric field processing on quality traits of beef muscles. Innov. Food Sci. Emerg. Technol. 2015, 29, 31-40. [CrossRef]

25. Juárez, M.; Polvillo, O.; Contò, M.; Ficco, A.; Ballico, S.; Failla, S. Comparison of four extraction/methylation analytical methods to measure fatty acid composition by gas chromatography in meat. J. Chromatogr. A 2008, 1190, 327-332. [CrossRef]

26. Penet, C.; Worthington, R.E.; Phillips, R.D.; Moon, N.J. Free amino acids of raw and cooked ground beef and pork. J. Food Sci. 1983, 48, 298-299. [CrossRef]

27. Pagès, J. Collection and analysis of perceived product inter-distances using multiple factor analysis: Application to the study of 10 white wines from the Loire Valley. Food Qual. Prefer. 2005, 16, 642-649. [CrossRef]

28. Shahidi, F.; Zhong, Y. Lipid oxidation and improving the oxidative stability. Chem. Soc. Rev. 2010, 39, 4067. [CrossRef]

29. Park, S.Y.; Yoo, S.S.; Uh, J.H.; Eun, J.B.; Lee, H.C.; Kim, Y.J.; Chin, K.B. Evaluation of Lipid Oxidation and Oxidative Products as Affected by Pork Meat Cut, Packaging Method, and Storage Time during Frozen Storage $\left(-10^{\circ} \mathrm{C}\right)$. J. Food Sci. 2007, 72, C114-C119. [CrossRef]

30. Wood, J.D.; Enser, M.; Fisher, A.V.; Nute, G.R.; Sheard, P.R.; Richardson, R.I.; Hughes, S.I.; Whittington, F.M. Fat deposition, fatty acid composition and meat quality: A review. Meat Sci. 2008, 78, 343-358. [CrossRef] 
31. Rhee, K.S.; Ziprin, Y.A.; Ordonez, G.; Bohac, C.E. Fatty acid profiles and lipid oxidation in beef steer muscles from different anatomical locations. Meat Sci. 1988, 23, 293-301. [CrossRef]

32. Badiani, A.; Stipa, S.; Bitossi, F.; Gatta, P.P.; Vignola, G.; Chizzolini, R. Lipid composition, retention and oxidation in fresh and completely trimmed beef muscles as affected by common culinary practices. Meat Sci. 2002, 60, 169-186. [CrossRef]

33. Ma, H.; Ledward, D.A.; Zamri, A.I.; Frazier, R.A.; Zhou, G.H. Effects of high pressure/thermal treatment on lipid oxidation in beef and chicken muscle. Food Chem. 2007, 104, 1575-1579. [CrossRef]

34. Kantono, K.; Hamid, N.; Oey, I.; Wang, S.; Xu, Y.; Ma, Q.; Faridnia, F.; Farouk, M. Physicochemical and sensory properties of beef muscles after Pulsed Electric Field processing. Food Res. Int. 2019, 121, 1-11. [CrossRef] [PubMed]

35. Kelly, M.J.; Tume, R.K.; Newman, S.A.; Thompson, J.M. Environmental effects on the fatty acid composition of subcutaneous beef fat. Aust. J. Exp. Agric. 2001, 41, 1023. [CrossRef]

36. Manner, W.; Maxwell, R.J.; Williams, J.E. Effects of Dietary Regimen and Tissue Site on Bovine Fatty Acid Profiles. J. Anim. Sci. 1984, 59, 109-121. [CrossRef]

37. Haffner, S.M. The Metabolic Syndrome: Inflammation, Diabetes Mellitus, and Cardiovascular Disease. Am. J. Cardiol. 2006, 97, 3-11. [CrossRef]

38. Enser, M.; Richardson, R.I.; Wood, J.D.; Gill, B.P.; Sheard, P.R. Feeding linseed to increase the n-3 PUFA of pork: Fatty acid composition of muscle, adipose tissue, liver and sausages. Meat Sci. 2000, 55, 201-212. [CrossRef]

39. Kim, S.R.; Jeon, S.Y.; Lee, S.-M. The association of cardiovascular risk factors with saturated fatty acids and fatty acid desaturase indices in erythrocyte in middle-aged Korean adults. Lipids Health Dis. 2015, 14, 133. [CrossRef]

40. Ma, Q.; Hamid, N.; Oey, I.; Kantono, K.; Farouk, M. The Impact of High-Pressure Processing on Physicochemical Properties and Sensory Characteristics of Three Different Lamb Meat Cuts. Molecules 2020, 25, 2665. [CrossRef]

41. Kanatt, S.R.; Chander, R.; Sharma, A. Effect of radiation processing of lamb meat on its lipids. Food Chem. 2006, 97, 80-86. [CrossRef]

42. Vasta, V.; Aouadi, D.; Brogna, D.M.; Scerra, M.; Luciano, G.; Priolo, A.; Salem, H.B. Effect of the dietary supplementation of essential oils from rosemary and artemisia on muscle fatty acids and volatile compound profiles in Barbarine lambs. Meat Sci. 2013, 95, 235-241. [CrossRef] [PubMed]

43. Alfaia, C.M.; Alfaia, C.M.; Alves, S.P.; Lopes, A.F.; Fernandes, M.J.; Costa, A.S.; Fontes, C.M.; Castro, M.L.; Bessa, R.J.; Prates, J.A. Effect of cooking methods on fatty acids, conjugated isomers of linoleic acid and nutritional quality of beef intramuscular fat. Meat Sci. 2010, 84, 769-777. [CrossRef] [PubMed]

44. Yang, Y.; Sun, Y.; Pan, D.; Wang, Y.; Cao, J. Effects of high pressure treatment on lipolysis-oxidation and volatiles of marinated pork meat in soy sauce. Meat Sci. 2018, 145, 186-194. [CrossRef] [PubMed]

45. He, Z.; Huang, Y.; Li, H.; Qin, G.; Wang, T.; Yang, J. Effect of high-pressure treatment on the fatty acid composition of intramuscular lipid in pork. Meat Sci. 2012, 90, 170-175. [CrossRef] [PubMed]

46. Yang, H.; Ma, C.; Qiao, F.; Song, Y.; Du, M. Lipolysis in intramuscular lipids during processing of traditional Xuanwei ham. Meat Sci. 2005, 71, 670-675. [CrossRef] [PubMed]

47. Leyton, J.; Drury, P.J.; Crawford, M.A. Differential oxidation of saturated and unsaturated fatty acids in vivo in the rat. Br. J. Nutr. 1987, 57, 383. [CrossRef] [PubMed]

48. Pereda, J.; Ferragut, V.; Quevedo, J.M.; Guamis, B.; Trujillo, A.J. Effects of Ultra-High-Pressure Homogenization Treatment on the Lipolysis and Lipid Oxidation of Milk during Refrigerated Storage. J. Agric. Food Chem. 2008, 56, 7125-7130. [CrossRef]

49. Tshabalala, P.A.; Strydom, P.E.; Webb, E.C.; De Kock, H.L. Meat quality of designated South African indigenous goat and sheep breeds. Meat Sci. 2003, 65, 563-570. [CrossRef]

50. Madruga, M.S.; Elmore, J.S.; Oruna-Concha, M.J.; Balagiannis, D.; Mottram, D.S. Determination of some water-soluble aroma precursors in goat meat and their enrolment on flavour profile of goat meat. Food Chem. 2010, 123, 513-520. [CrossRef]

51. Trani, A.; Gambacorta, G.; Loizzo, P.; Alviti, G.; Schena, A.; Faccia, M.; Aquilanti, L.; Di Luccia, A. Biochemical Traits of Ciauscolo, a Spreadable Typical Italian Dry-Cured Sausage. J. Food Sci. 2010, 75, C514-C524. [CrossRef] [PubMed] 
52. Holló, G.; Nuernberg, K.; Holló, I.; Csapó, J.; Seregi, J.; Repa, I.; Ender, K. Effect of feeding on the composition of longissmus muscle of Hungarian Grey and Holstein Friesian bulls.-III. Amino acid composition and mineral content. Arch. Anim. Breed. 2007, 50, 575-586.

53. Watanabe, A.; Ueda, Y.; Higuchi, M. Effects of slaughter age on the levels of free amino acids and dipeptides in fattening cattle. Anim. Sci. J. 2004, 75, 361-367. [CrossRef]

54. Aristoy, M.C.; Toldrá, F. Concentration of free amino acids and dipeptides in porcine skeletal muscles with different oxidative patterns. Meat Sci. 1998, 50, 327-332. [CrossRef]

55. Franco, D.; Gonzalez, L.; Bispo, E.; Rodriguez, P.; Garabal, J.I.; Moreno, T. Study of hydrolysed protein composition, free amino acid, and taurine content in different muscles of galician blonde beef. J. Muscle Foods 2010, 21, 769-784. [CrossRef]

56. Cornet, M.; Bousset, J. Free amino acids and dipeptides in porcine muscles: Differences between 'red' and 'white' muscles. Meat Sci. 1999, 51, 215-219. [CrossRef]

57. Elgasim, E.; Alkanhal, M. Proximate composition, amino acids and inorganic mineral content of Arabian Camel meat: Comparative study. Food Chem. 1992, 45, 1-4. [CrossRef]

58. Sales, J.; Hayes, J.P. Proximate, amino acid and mineral composition of ostrich meat. Food Chem. 1996, 56, 167-170. [CrossRef]

59. Liu, T.; Hamid, N.; Kantono, K.; Pereira, L.; Farouk, M.M.; Knowles, S.O. Effects of meat addition on pasta structure, nutrition and in vitro digestibility. Food Chem. 2016, 213, 108-114. [CrossRef]

60. Luo, Q.; Hamid, N.; Oey, I.; Leong, S.Y.; Kantono, K.; Alfaro, A.; Lu, J. Physicochemical changes in New Zealand abalone (Haliotis iris) with pulsed electric field (PEF) processing and heat treatments. LWT 2019, 115, 108438. [CrossRef]

61. Toldra, F. Proteolysis and lipolysis in flavour development of dry-cured meat products. Meat Sci. 1998, 49, S101-S110. [CrossRef]

62. Koutsidis, G.; Elmore, J.S.; Oruna-Concha, M.J.; Campo, M.M.; Wood, J.D.; Mottram, D.S. Water-soluble precursors of beef flavour. Part II: Effect of post-mortem conditioning. Meat Sci. 2008, 79, 270-277. [CrossRef] [PubMed]

63. Herranz, B.; de la Hoz, L.; Hierro, E.; Fernández, M.; Ordonez, J.A. Improvement of the sensory properties of dry-fermented sausages by the addition of free amino acids. Food Chem. 2005, 91, 673-682. [CrossRef]

64. Yang, Y.; Ye, Y.; Wang, Y.; Sun, Y.; Pan, D.; Cao, J. Effect of high pressure treatment on metabolite profile of marinated meat in soy sauce. Food Chem. 2018, 240, 662-669. [CrossRef] [PubMed]

65. Lin, Y.H.T.; Hamid, N.; Shepherd, D.; Kantono, K.; Spence, C. Environmental sounds influence the multisensory perception of chocolate gelati. Foods 2019, 8, 124. [CrossRef] [PubMed]

66. Limbad, M.; Gutierrez Maddox, N.; Hamid, N.; Kantono, K. Sensory and Physicochemical Characterization of Sourdough Bread Prepared with a Coconut Water Kefir Starter. Foods 2020, 9, 1165. [CrossRef] [PubMed]

67. Gao, Y.; Hamid, N.; Gutierrez-Maddox, N.; Kantono, K.; Kitundu, E. Development of a probiotic beverage using breadfruit flour as a substrate. Foods 2019, 8, 214. [CrossRef] [PubMed]

(C) 2020 by the authors. Licensee MDPI, Basel, Switzerland. This article is an open access article distributed under the terms and conditions of the Creative Commons Attribution (CC BY) license (http://creativecommons.org/licenses/by/4.0/). 